Article

\title{
Analytic Hierarchy Process-Based Airport Ground Handling Equipment Purchase Decision Model
}

\author{
Yu-Jwo Tao ${ }^{1}$, Hsuan-Shih Lee ${ }^{1}$ and Chang-Shu Tu ${ }^{2, *(D)}$ \\ 1 Department of Shipping and Transportation Management, National Taiwan Ocean University, No. 2, \\ Pei-Ning Road, Keelung City 202301, Taiwan; ta794260@gmail.com (Y.-J.T.); hslee@email.ntou.edu.tw (H.-S.L.) \\ 2 Department of Information Management, Chang Gung University, No .259, WenHwa 1st Road, KweiShan, \\ Taoyuan City 33302, Taiwan \\ * Correspondence: long.tree@msa.hinet.net; Tel.: +886-927351833
}

Citation: Tao, Y.-J.; Lee, H.-S.; Tu, C.-S. Analytic Hierarchy

Process-Based Airport Ground

Handling Equipment Purchase Decision Model. Sustainability 2021, 13, 2540. https://doi.org/10.3390/ su13052540

Academic Editors: Dragan Pamucar, Željko Stević and Marc A. Rosen

Received: 30 December 2020

Accepted: 22 February 2021

Published: 26 February 2021

Publisher's Note: MDPI stays neutral with regard to jurisdictional claims in published maps and institutional affiliations.

Copyright: (c) 2021 by the authors. Licensee MDPI, Basel, Switzerland. This article is an open access article distributed under the terms and conditions of the Creative Commons Attribution (CC BY) license (https:/ / creativecommons.org/licenses/by/ $4.0 /)$.

\begin{abstract}
The Airport ground handling services (AGHS) equipment supplier provider selection requires a safety guarantee in terms of the daily operations AGHS provider. AGHS providers seek to avoid aircraft damage and airline delays and ensure the provision of reliable and high-quality services. The primary objective of this paper was to develop purchasing decision model of the analytic hierarchy process (AHP), AHP-fuzzy linear programming (FLP), and AHP-Taguchi loss function (TLF) multi-choice goal programming (MCGP) purchase decision models to help the AGHS purchasing managers in selecting the best AGHS equipment supplier provider. The constructed models were assessed, and results obtained for the AHP-FLP and AHP-TLF-MCGP models were compared. We conducted a real-world example of supplier selection by an AGHS company by using the proposed models. The proposed model provides useful information and has practical value for AGHS providers.
\end{abstract}

Keywords: equipment purchase decision; analytic hierarchy process; Taguchi loss function; fuzzy linear programming; multi-choice goal programming

\section{Introduction}

The Airport ground handling service (AGHS) companies are responsible for varied ground handling service activities. Ground handling operations can be categorized as either terminal or airside operations. In this study, we focused on decision models for identifying the best suppliers of equipment for airside operations. Ramp handling, a major task performed by AGHS companies [1], involves aircraft loading and unloading operations as well as passenger, crew, baggage, and freight (e.g., mail) transport between aircraft and terminal buildings [2]. Ramp handling classified as a logistics service, and it be offered by a third-party service provider ground handler service company (i.e., the AGHS company), an airline company (self-handling), or a ramp handling company within an airport [3,4].

AGHS duties are difficult for ground handlers whose work safety relies on technologically advanced equipment. Furthermore, AGHS companies experience anxieties with the ground handler service performance and quality of equipment. In addition, purchasing managers at AGHS companies select equipment suppliers with favorable reputations, and they have two reasons for doing so. First, the use of high-quality AGHS equipment can increase the safety of ground handling operations. Second, such supplier performs quality assurance, indicating that their equipment is of a high quality, and this can inspire confidence in AGHS providers and the airlines that pay for such services. AGHS equipment supplier selection (AGHSESS) problem has a marked effect on AGHS quality, and it is influenced by several factors. Such factors include a supplier's manufacturing performance, the supplier's industry reputation, and the supplier's produce quality and price [5]. In general, multiple-criteria decision-making (MCDM) methods assistance decision-makers (DMs) make estimations related to a list of options. Depending on the purchasing conditions, 
certain criteria have different levels of importance, thus necessitating criteria weighting [6,7]. Optimal AGHSESS is an MCDM problem [8]. AGHSESS problem participate a vital role in the decision-making process of an AGHS provider; however, optimal AGHSESS is a time wasting and difficult procedure that requires relevant experience and an understanding of the industry, and this task can be difficult for AGHS purchasing managers [9]. This study motivation has proposed an effective decision model for AGHSESS in order to enable DMs make decisions in scenarios that involve the consideration of numerous factors and the assessment of a substantial body of information and records [10]. The subsequently section presents a review of the related value of literature.

\section{Literature Review}

Supplier selection (SC) is extensively discussed in the literature. For example, Monczka et al. [11] suggested the use of factor analysis for assessing the value of suppliers. Vonderembse and Tracey [12] conducted a study involving 268 purchasing managers to determine their supplier selection criteria when suppliers constantly endeavored to improve their products. Suppliers can obtain information on buyer requirements, traditions, and decisionmaking patterns, and this can help them alter and better apply their resources. Such information is advantageous to suppliers [12], because it enables them to clearly understand customer needs. Bhutta and Huq [13] highlighted two main approaches that managers can use to construct decision criteria while considering supplier choices; one of the approaches involves considering the total cost of ownership, and the other is based on a hierarchical procedure. Sarkis and Talluri [14] used an analytic network process (ANP) decision model to perform a strategic supplier selection.

Although the AGHSESS is an important consideration among AGHS providers, publications on this topic are limited. Some studies have provided useful information pertaining to equipment supplier evaluations. For example, Sevkli et al. [5] applied a mixed technique (e.g., AHP-fuzzy linear programming (FLP) model to resolve the vendor choice problems. When the conventional AHP is used, AGHSESS is based on only price and reputation. Specifically, a buyer company must implement optimal supplier selection to increase their efficiency in response to uncertainty and resource constraints. Accordingly, the AHP-FLP technique is more useful than the conventional AHP techniques [7]. Goztepe and Kahraman [15] considered the military DM processes for battlefield operations and operations planning. Ordoobadi [16] combined the AHP and Taguchi loss function (TLF) to rank potential suppliers for outsourcing purposes. Furthermore, Liao and Kao [17] integrated AHP, TLF, and multi-choice goal programming (MCGP) models to resolve provider choice problems. Magdalena [18] combined the TLF and FLP to identify the optimal supplier in a given situation. By combing the TLF and AHP, Ordoobadi [19] provided an approach for ranking technology choices for achievement intentions. However, few investigations of AGHSESS and related techniques in practice have been published. To block this gap in the past literature, this paper applied an AHP-FLP and AHP-TLF-MGCP model in the context of a Taiwanese AGHS provider. Our main goal was to help the purchasing managers of such companies' use straightforward techniques to identify the most suitable equipment suppliers. For the sake of reducing the AHP and AHP-FLP model approaches drawbacks and reach precise results, we are using the AHPTLF-MCGP model to validate of the AGHSESS problem. Our AHP-TLF-MGCP model can provide a valuable reference that allows DMs to set various desire levels for related equipment suppliers and buyers.

The rest of this manuscript is organized as follows: Section 2 summarizes the proposed methods; Section 3 details the proposed model for AGHSESS problems. In Section 4, presents findings related how to the use of the AHP-FLP and AHP-TLF-MGCP approaches to solve AGHSESS problems. We also explain the practical value of this approach in a real-world case. Lastly, conclusions and implications are presented in Section 5. 


\section{Methods}

In this methods section, we explain how the AHP, AHP-FLP, and AHP-TLF-MGCP purchase decision models can be used to solve the aforementioned AGHSESS problem.

\subsection{AHP Technique}

The AHP technique is a judgment-based technique established by Saaty [20] for dealing with composite, and MDCM problems. The AHP is founded on three concepts: The formation of the model, a relative decision based on certain criteria, and a combination of the precedence. The AHP has been used to solve diverse MCDM problems [21-24].

Saaty [25] stated that in many real-world cases, the pair-wise decisions of DMs have several levels of ambiguity. Generally, the executive team tasked with AGHSESS is confident about the ranking of the assessment elements but unsure of whether the mathematical assessments related to such decisions are accurate. The traditional AHP-based approach to overcoming this issue is to introduce a distinct linguistic assessment of decisions. In preference to straight allocating numerical values to the comparison ratios, the AGHS equipment executive team selects a suitable linguistic expression that corresponds most to the decision options.

\subsection{TLF Method}

The TLF method for assessing loss as an outcome of a product does not meet any regulatory terms [26]. Loss calculation is conducted to quantitatively evaluate the loss of quality caused by inconsistencies between the specified quality and actual quality of a product.

In general, three styles of loss function are used to calculate Taguchi loss [27-29]. First, a two-sided loss function is used; in this function, a supposed value is the goal and deviation from either side of the goal is permitted provided that it remains within the speciation limits. In this study, quality loss functions were used to quantify the effect of AGHSESS tasks.

\subsection{Fuzzy FLP Method}

Bellman and Zadeh [30] proposed a fuzzy programming model for DM in the context of a fuzzy situation. Their method was used by Zimmermann [31] to solve FLP problems [10].

We used an AHP-weighted FLP model (hereafter referred to as AHP-FLP model) in our study to solve AGHSESS problems of practical importance to an AGHS provider in Taiwan. This work represents an attempt to overcome real-world obstacles encountered in the use of an AHP-FLP technique.

\subsection{MCGP Approach}

Scholars have devised many modified goal programming methods using MCGP. To recover the utility of goal programming (GP) methods, Chang [32] developed a model for resolve the multi-objective decision-making (MODM) problems using multi-choice aspiration levels (MCALs). Chang's proposal to solve MODM problems using MCALs differs considerably from a fuzzy goal programming approach in that their model incorporates membership functions (MFs) to address MODM problems with imprecise goal aspiration levels. The following equations address this issue based on a typical MCGP problem:

$$
\text { Minimize } \sum_{i=1}^{n}\left[\left(d_{i}^{+}+d_{i}^{-}\right)+\left(e_{i}^{+}+e_{i}^{-}\right)\right]
$$

Subject to

$$
\begin{gathered}
f_{i}(X) b_{i}-d_{i}^{+}+d_{i}^{-}=b_{i} y_{i} i=1,2, \ldots, n, \\
y_{i}-e_{i}^{+}+e_{i}^{-}=g_{i, \min } i=1,2, \ldots, n, \\
g_{i, \min } \leq y_{i} \leq g_{i, \max } i=1,2, \ldots, n,
\end{gathered}
$$




$$
d_{i}^{+}, d_{i}^{-}, e_{i}^{+}, e_{i}^{-} \geq 0, i=1,2, \ldots, n
$$

$X \in F$ where $F$ is an achievable set and $X$ has no symbol constraints.

Refer to the case regarding the managerial implications of constraints in [32].

\section{Proposed Model}

The proposed model is on the foundation of AHP-FLP methodology for solving AGHSESS problems. The model procedure is described as follows.

\subsection{Format of the AHP-FLP Purchase Decision Model Process Based on AHP-FLP}

The model for the AGHSESS problem and the AHP-FLP model involves three essential phases: (1) Identifying the criteria chosen in the purchase decision model, (2) conducting AHP calculations, (3) and making optimal decisions using the AHP-FLP approach this will help the AGHS provider. The entire AHP process is detailed in [5].

In this proposed model section, the general multi-purpose fuzzy model for AGHSESS is current in the tracking method $[5,7,33,34]$. The fuzzy multi-objective formulation for the aforementioned selection problems is derived as follows:

Obtain a vector $X$, where $X$ is $\left[x_{1}, x_{2}, x_{3}, \ldots x_{n}\right]$ that exploits the AGHSESS goal utility function $z_{k}$ with a number of $m$ criteria [5]:

$$
\operatorname{Max} \widetilde{z}_{k}=\sum_{i=1}^{n}\left(c_{k i} \times x_{i}\right) \geq \sim z_{k}^{0} k=1,2,3, \ldots, n
$$

The following tracking constraints are applied:

$$
\sum_{i=1}^{n} a_{r i} \times x_{i} \leq b_{r}
$$

where $c_{k i}, a_{r i}$, and $b_{r}$ are crisp values.

In this proposed model, $\sim$ signifies the fuzzy situation. The symbol $\geq \sim$ denotes the fuzzified (i.e., unclear or fuzzy) edition of $\geq$ and indicate adequately equipped or better. $Z_{k}^{0}$ is the rank that the DM desires to achieve.

All goal purpose values, $\tilde{z}_{k}$, are adjusted linearly from $z_{k}^{\min }$ to $z_{k}^{\max }$. Such values may be treated similar to fuzzy numerals in relation to the linear membership function (LMF) as presented in Figure 1.

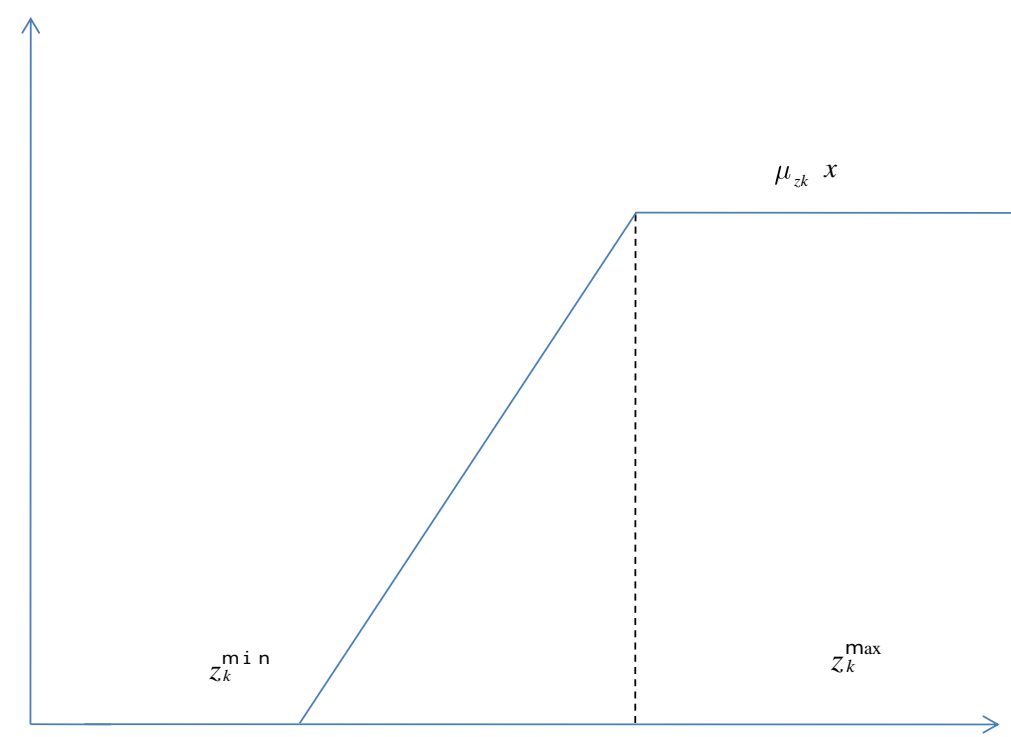

Figure 1. Maximizing objective function as fuzzy number. 
As described in the aforementioned LMF, maximization aspirations $\left(\widetilde{z}_{k}\right)$ are given as follows:

$$
\mu_{z 1}(x)=\left\{\begin{array}{ccc}
1 & \begin{array}{c}
\text { for } z_{k} \geq z_{k}^{\max } \\
\left(z_{k}^{\max }-z_{k}(x)\right)
\end{array} /\left(z_{k}^{\max }-z_{k}^{\min }\right) \text { for } \begin{array}{c}
z_{k}^{\min }<z_{k}<z_{k}^{\max } \\
\text { for } z_{k} \leq z_{k}^{\min }
\end{array}
\end{array}\right.
$$

The decision model presented in Equations (6) and (7) be present constructed using the weighted additive model, which is broadly used to address vector optimization problems; the essential idea is to use a single efficacy purpose to precise the general preferences of the DM to elucidate the significance of certain criteria [5,35]. In this methodology, all fuzzy MFs must be derived in terms of their relative weights, and subsequently, the derivation results must be added to obtain a linear weighted function.

$$
\max \sum_{k=1}^{m}\left(w_{k} \times \lambda_{k}\right)
$$

subject to:

$$
\begin{gathered}
\lambda_{k} \leq \mu_{z k}(x) \\
\lambda_{k} \in[0,1] \text { and } k=1,2,3, \ldots n \\
\sum_{k=1}^{m} w_{k}=1, w_{k} \geq 0 \\
x_{i} \geq 0, i=1,2,3, \ldots m
\end{gathered}
$$

where $w_{k}$ and $\mu_{z k}(x)$ denote the resolution of the MF and the weighted coefficients that have a crucial relationship with the fuzzy objectives and membership functions.

In the third phased of the proposed approach, the AHP-FLP decision model helps the AGHS provider make optimal purchase decisions. The operating procedures of this AHP-FLP decision model are as follows:

Step 1:An AGHSESS criterion is selected for determining the hierarchical construction for the choice of the finest supplier.

Step 2:The team of experts and researchers conduct weight computation for the criteria at various hierarchical levels to determine the general achievements for each AGHS equipment supplier by conducting pairwise comparisons of the major decision criteria.

Step 3: According to the criteria identified for related equipment selection, the AGHSESS purchase decision model is constructed.

Step 4:Define the lower bound $\left(z_{k}^{\min }\right)$ and upper bound $\left(z_{k}^{\max }\right)$ multi-objective purchase decision problem is similar to a single-objective linear programming model.

Step 5: $z_{k}^{\min }$ and $z_{k}^{\max }$ assessments are used to obtain the LMF for the criterion in Equation (8). Step 6: On the basis of the weighted additive model, we create the corresponding crispy typical of the fuzzy optimization problem using Equations (6)-(13).

Step 7: We identify the best result vector $X$, which represents the expert decision on the unique purchase decision problem.

Step 8: We compare the AHP and AHP-FLP models.

Step 9: On the basis of the results of the AHP-FLP model, we construct the AHP-TLFMCGP model to solve the AGHSESS problem according to Equations (1)-(5). The loss function, weighted Taguchi values, and normalized values derived in the calculation are summarized in Tables 1-12 (further details on the procedure are provided in [19]).

Step 10:The results obtained using the AHP-FLP model and AHP-TLF-MCGP models are compared. 
Table 1. Equipment supplier decision criteria.

\begin{tabular}{ll}
\multicolumn{1}{c}{$\begin{array}{c}\text { Equipment Supplier } \\
\text { Decision Criteria }\end{array}$} & \multicolumn{1}{c}{ Quality Guarantee Definition } \\
\hline $\begin{array}{l}\text { Quality } \\
\text { management }\end{array}$ & $\begin{array}{l}\text { system (ISO/TS 16 Quality guarantee system(ISO/TS } \\
16949 / \text { QS-9000/ISO 14001) policy and domestic } \\
\text { quality inspections. }\end{array}$ \\
\hline & $\begin{array}{l}\text { Producing ability contain high-quality utilize of statistical } \\
\text { process control (SPC), lean manufacturing and a "kanban" } \\
\text { system. Supplier novelty abilities comprise hardware, } \\
\text { software (CAD/CAE/CAM), information, works and skill. } \\
\text { maintenance } \\
\text { The fix and preservation examine sustains } \\
\text { customer agreement. }\end{array}$ \\
\hline Product warranty & $\begin{array}{l}\text { Suppliers trail assurances and include an assessment } \\
\text { procedure to define what forces enhancements in assurance } \\
\text { expenses and buyer agreement }\end{array}$ \\
\hline Provide technical transfer & $\begin{array}{l}\text { The scientific compatibility of the overhaul, the substantial or } \\
\text { the parts that are affording to the retail corporation is vital. }\end{array}$ \\
\hline $\begin{array}{l}\text { Good cooperative relationship } \\
\text { and reputation }\end{array}$ & $\begin{array}{l}\text { A durable and flouring buyer/supplier association needs } \\
\text { shared reliance and consideration } \\
\text { The provider has a fine financial situation in } \\
\text { the manufacturing }\end{array}$ \\
\hline Reasonable parts price & The supplier provides reasonable parts prices. \\
\hline
\end{tabular}

Table 2. Criteria matrix.

\begin{tabular}{ccccccc}
\hline & Quality & Maintenance & Warranty & Technical & Reputation & Price \\
\hline Quality & 1 & 2 & 3 & $1 / 2$ & 4 & $1 / 3$ \\
Maintenance & $1 / 2$ & 1 & $1 / 2$ & $1 / 4$ & 2 & $1 / 7$ \\
Warranty & $1 / 3$ & 2 & 1 & $1 / 3$ & 2 & $1 / 6$ \\
Technical & 2 & 4 & 3 & 1 & 6 & $1 / 2$ \\
Reputation & $1 / 4$ & $1 / 2$ & $1 / 2$ & $1 / 6$ & 1 & $1 / 9$ \\
Price & 3 & 7 & 6 & 2 & 9 & 1 \\
\hline
\end{tabular}

Table 3. Pair-wise comparision template criteria.

\begin{tabular}{cccc}
\hline Supplier Criteria & Weights $(w)$ & $\lambda_{\max }, \mathbf{C I}, \mathbf{R I}$ & CR \\
\hline SC1 (Quality) & 0.151 & $\lambda_{\max }=6.521$ & \\
SC2 (Maintenance) & 0.062 & & \\
SC3 (Warranty) & 0.079 & $\mathrm{CI}=0.104$ & 0.084 \\
SC4 (Technical) & 0.241 & $\mathrm{RI}=1.24$ & \\
SC5 (Reputation) & 0.039 & & \\
SC6 (Price) & 0.428 & & \\
\hline
\end{tabular}

Table 4. Adjusted template [37].

\begin{tabular}{cccccccc}
\hline & Quality & Maintenance & Warranty & Technical & Reputation & Price & (Weights Row Average) \\
\hline Quality & 0.141 & 0.121 & 0.214 & 0.120 & 0.167 & 0.148 & 0.152 \\
Maintenance & 0.071 & 0.061 & 0.036 & 0.060 & 0.083 & 0.063 & 0.062 \\
Warranty & 0.047 & 0.121 & 0.071 & 0.060 & 0.083 & 0.074 & 0.079 \\
Technical & 0.282 & 0.242 & 0.214 & 0.240 & 0.250 & 0.222 & 0.241 \\
Reputation & 0.035 & 0.030 & 0.036 & 0.040 & 0.042 & 0.049 & 0.039 \\
Price & 0.424 & 0.424 & 0.429 & 0.480 & 0.375 & 0.444 & 0.428 \\
\hline
\end{tabular}


Table 5. Pair-wise evaluate assessment of suppliers with regard to all evaluation criteria. [38].

\begin{tabular}{|c|c|c|c|c|}
\hline DMU & Supplier1 & Supplier2 & Supplier3 & AHP Weights \\
\hline \multicolumn{5}{|l|}{ Quality } \\
\hline Supplier1 & 1 & 3 & 5 & 0.633 \\
\hline Supplier2 & $1 / 3$ & 1 & 3 & 0.260 \\
\hline Supplier3 & $1 / 5$ & $1 / 3$ & 1 & 0.106 \\
\hline Consistency ratio & & & & 0.033 \\
\hline \multicolumn{5}{|l|}{ Maintenance } \\
\hline Supplier1 & 1 & $1 / 3$ & $1 / 9$ & 0.077 \\
\hline Supplier2 & 3 & 1 & $1 / 3$ & 0.231 \\
\hline Supplier3 & $1 / 9$ & 3 & 1 & 0.692 \\
\hline Consistency ratio & & & & 0.000 \\
\hline \multicolumn{5}{|l|}{ Warranty } \\
\hline Supplier1 & 1 & $1 / 5$ & $1 / 9$ & 0.064 \\
\hline Supplier2 & 5 & 1 & $1 / 3$ & 0.267 \\
\hline Supplier3 & 9 & 3 & 1 & 0.669 \\
\hline Consistency ratio & & & & 0.025 \\
\hline \multicolumn{5}{|l|}{ Technical } \\
\hline Supplier1 & 1 & $1 / 9$ & $1 / 7$ & 0.057 \\
\hline Supplier2 & 9 & 1 & 3 & 0.649 \\
\hline Supplier3 & 7 & $1 / 3$ & 1 & 0.295 \\
\hline Consistency ratio & & & & 0.070 \\
\hline \multicolumn{5}{|l|}{ Reputation } \\
\hline Supplier1 & 1 & $1 / 5$ & $1 / 4$ & 0.096 \\
\hline Supplier2 & 5 & 1 & 3 & 0.619 \\
\hline Supplier3 & 4 & $1 / 3$ & 1 & 0.284 \\
\hline Consistency ratio & & & & 0.0923 \\
\hline \multicolumn{5}{|l|}{ Price } \\
\hline Supplier1 & 1 & 3 & 5 & 0.633 \\
\hline Supplier2 & $1 / 3$ & 1 & 3 & 0.260 \\
\hline Supplier3 & $1 / 5$ & $1 / 3$ & 1 & 0.106 \\
\hline Consistency ratio & & & & 0.0419 \\
\hline
\end{tabular}

Table 6. Overall score calculation.

\begin{tabular}{cccccccc}
\hline & Quality & Maintenance & Warranty & Technical & Reputation & Price & Score \\
\hline Supplier A1 & 0.096 & +0.005 & +0.005 & +0.014 & +0.004 & +0.271 & $=0.395^{*}$ \\
Supplier A2 & 0.039 & +0.014 & +0.021 & +0.156 & +0.024 & +0.111 & $=0.365$ \\
Supplier A3 & 0.016 & +0.043 & +0.053 & +0.071 & +0.011 & +0.045 & $=0.239$ \\
Rrow & $0.151^{* *}$ & 0.062 & 0.079 & 0.241 & 0.039 & 0.428 & \\
Average & & & & & & & \\
\hline
\end{tabular}

Notes: $1.0 .395^{*}=0.633 \times 0.151=0.096+0.077 \times 0.062=0.005+0.064 \times 0.079=0.005+0.057 \times 0.241=0.014+0.096 \times 0.039=0.004+$ $0.633 \times 0.428=0.271 .2 .0 .151^{* *}=0.096+0.039+0.016$.

Table 7. Input data for airport ground handling service equipment supplier selection.

\begin{tabular}{ccccccc}
\hline & Quality & Maintenance & Warranty & Technical & Reputation & Price \\
\hline $\begin{array}{c}\text { Supplier1 } \\
\left(x_{1}\right)\end{array}$ & 0.096 & 0.005 & 0.005 & 0.014 & 0.004 & 0.271 \\
\hline $\begin{array}{c}\text { Supplier2 } \\
\left(x_{2}\right)\end{array}$ & 0.039 & 0.014 & 0.021 & 0.156 & 0.024 & 0.111 \\
\hline $\begin{array}{c}\text { Supplier3 } \\
\left(x_{3}\right)\end{array}$ & 0.016 & 0.043 & 0.053 & 0.071 & 0.011 & 0.045 \\
\hline $\begin{array}{c}\text { Row } \\
\text { Averages }\end{array}$ & 0.151 & 0.062 & 0.079 & 0.241 & 0.039 & 0.428 \\
\hline
\end{tabular}


Table 8. Dataset used for representing the utilities relationships.

\begin{tabular}{ccc}
\hline Lower $\left(z_{k}^{\min }\right)$ and Upper $\left(z_{k}^{\max }\right)$ Bounds & $z_{k}^{\min }(\mu=0)$ & $z_{k}^{\max }(\mu=1)$ \\
\hline$z_{1}$-Quality & 0.016 & 0.096 \\
$z_{2}$-Maintenance & 0.005 & 0.043 \\
$z_{3}$-Warranty & 0.005 & 0.053 \\
$z_{4}$-Technical & 0.014 & 0.156 \\
$z_{5}$ - Reputation & 0.004 & 0.024 \\
$z_{6}$-Price & 0.045 & 0.271 \\
\hline
\end{tabular}

Table 9. Decision-maker's (DM's) perception of supplier performance related to six criteria.

\begin{tabular}{lcccccc}
\hline & Quality & Maintenance & Warranty & Technical & Reputation & Price \\
\hline Supplier1 & 90 & 65 & 90 & 65 & 70 & 92 \\
Supplier2 & 85 & 70 & 94 & 75 & 75 & 90 \\
Supplier3 & 92 & 72 & 96 & 70 & 80 & 94 \\
\hline
\end{tabular}

Table 10. Taguchi parameters for the six criteria.

\begin{tabular}{lccccc}
\hline & Target Value & Range & $\begin{array}{c}\text { Specifiction Limit for } \\
\text { the Deviation }\end{array}$ & Loss Coefficient \\
\hline Criteria & $\mathbf{( \% )}$ & $\mathbf{( \% )}$ & $\mathbf{( \% )}$ & $\mathbf{( k )}$ & Taguchi Loss Function $^{\text {(\%) }}$ \\
\hline Quality & 100 & $100 \sim 85$ & 15 & 2500 & $\mathrm{~L}(\mathrm{X})=2500(\mathrm{X}-\mathrm{T})^{2}$ \\
Maintenance & 100 & $100 \sim 70$ & 70 & 400 & $\mathrm{~L}(\mathrm{X})=400(\mathrm{X}-\mathrm{T})^{2}$ \\
Warranty & 100 & $100 \sim 90$ & 10 & 10,000 & $\mathrm{~L}(\mathrm{X})=10,000(\mathrm{X}-\mathrm{T})^{2}$ \\
Technical & 100 & $100 \sim 85$ & 15 & 625 & $\mathrm{~L}(\mathrm{X})=625(\mathrm{X}-\mathrm{T})^{2}$ \\
Reputation & 100 & $100 \sim 80$ & 20 & 1111 & $\mathrm{~L}(\mathrm{X})=1111.11(\mathrm{X}-\mathrm{T})^{2}$ \\
Price & 100 & $100 \sim 90$ & 10 & & $\mathrm{~L}(\mathrm{X})=10,000(\mathrm{X}-\mathrm{T})^{2}$ \\
\hline
\end{tabular}

Table 11. Individual and weighted loss scores for the six criteria.

\begin{tabular}{cccccccccccccccc}
\hline & \multicolumn{2}{c}{ Quality } & \multicolumn{2}{c}{ Maintenance } & \multicolumn{2}{c}{ Warranty } & \multicolumn{2}{c}{ Technical } & \multicolumn{2}{c}{ Reputation } & \multicolumn{2}{c}{ Price } & Weighted Score & Normalized \\
\hline Supplier & Weight & Loss & Weight & Loss & Weight & Loss & Weight & Loss & Weight & Loss & Weight & Loss & \\
\hline Supplier1 & 0.151 & 25 & 0.062 & 49 & 0.079 & 100 & 0.241 & 76.56 & 0.039 & 99.99 & 0.428 & 64 & 64.46 & 0.381 \\
Supplier2 & 0.151 & 56.25 & 0.062 & 36 & 0.079 & 36 & 0.241 & 39.06 & 0.039 & 69.44 & 0.428 & 100 & 68.49 & 0.405 \\
Supplier3 & 0.151 & 16 & 0.062 & 31.36 & 0.079 & 16 & 0.241 & 56.25 & 0.039 & 44.44 & 0.428 & 36 & 36.32 & 0.215 \\
\hline
\end{tabular}

Table 12. Analytic hierarchy process (AHP)-Taguchi loss function (TLF)-multi-choice goal programming (MCGP) model solution programming.

\begin{tabular}{ll}
\hline \multicolumn{1}{c}{ AHP-TLF-MCGP Model Solution Programming } & \multicolumn{1}{c}{ AHP-TLF-MCGP Model Goal } \\
\hline Min $z=$ & \\
$\left(w_{1}\left(0.151\left(\mathrm{dp}_{1}+\mathrm{dn}_{1}+\mathrm{ep}_{1}+\mathrm{en}_{1}\right)\right)\right.$ & Satisfy quality goal \\
$+\left(0.062\left(\mathrm{dp}_{2}+\mathrm{dn}_{2}+\mathrm{ep}_{2}+\mathrm{en}_{2}\right)\right)$ & Satisfy maintenance goal \\
$+\left(0.079\left(\mathrm{dp}_{3}+\mathrm{dn}_{3}+\mathrm{ep}_{3}+\mathrm{en}_{3}\right)\right)$ & Satisfy warranty goal \\
$+\left(0.241\left(\mathrm{dp}_{4}+\mathrm{dn}_{4}+\mathrm{ep}_{4}+\mathrm{en}_{4}\right)\right)$ & Satisfy technical goal \\
$+\left(0.039\left(\mathrm{dp}_{5}+\mathrm{dn}_{5}+\mathrm{ep}_{5}+\mathrm{en}_{5}\right)\right)$ & Satisfy reputation goal \\
$+\left(0.428\left(\mathrm{dp}_{6}+\mathrm{dn}_{6}+\mathrm{ep}_{6}+\mathrm{en}_{6}\right)\right)$ & Satisfy price goal \\
$+\left(\left(w_{2}\left(\mathrm{dp} \mathrm{p}_{7}+\mathrm{dn}_{7}+\mathrm{ep}_{7}+\mathrm{en}_{7}\right)\right)\right)$ & Satisfy loss function goal \\
$\mathrm{s.t}$ & \\
$w_{1}+w_{2}=1 ; w_{1}=0.8 ; w_{2}=0.2$ & \\
$\left(0.096 x_{1}+0.039 x_{2}+0.016 x_{3}\right) b_{1}-\mathrm{dp} p_{1}+\mathrm{dn}_{1}=y_{1} b_{1}$ & \\
$y_{1}-\mathrm{ep} 1+\mathrm{en}_{1}=0.096$ & For quality goal, the less the better \\
$y_{1}<=0.096$ & For $\left|y_{1}-g_{1, \text { min }}\right|$ \\
$0.016<=y_{1}$ & For bound of the $y_{1}$ \\
$\left(0.005 x_{1}+0.014 x_{2}+0.043 x_{3}\right) b_{2}-\mathrm{dp}_{2}+\mathrm{dn}_{2}=y_{2} b_{2}$ & \\
\hline
\end{tabular}


Table 12. Cont.

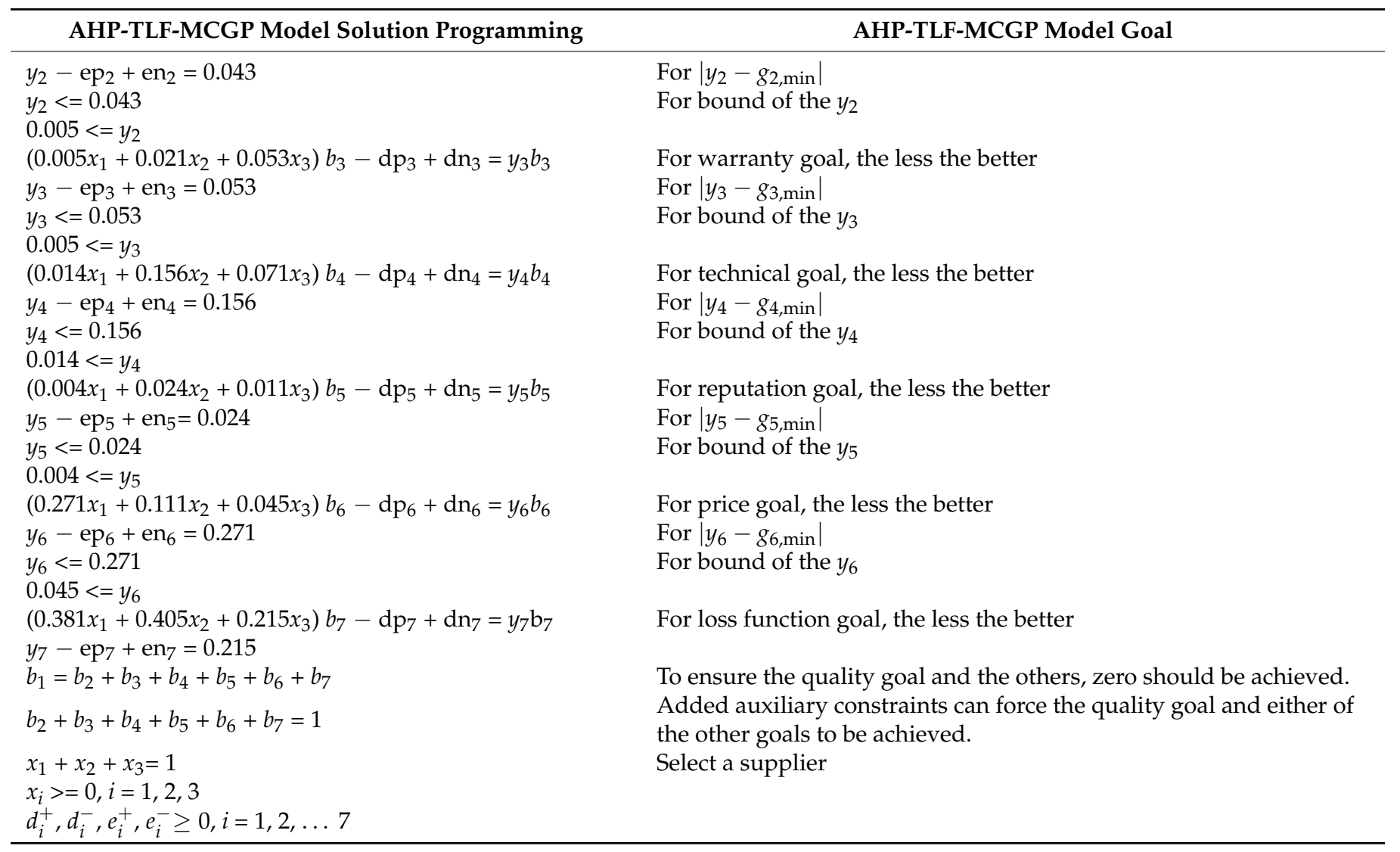

The general steps of the AHP-FLP and AHP-TLF-MCGP models are summarized in Figure 2.

\subsection{Real-World Application of the Proposed Model}

We conducted a case study on Taoyuan International Airport Services Co., Ltd. (TIAS) Taoyuan city, Taiwan, constituting the AGHS. In 2018, TIAS provided ground handling services for 81,789 flights, serviced over 27.2 million passengers, and handled over 1.82 million tons of cargo. TIAS has powered (vehicle quantity: 749) and nonpowered (vehicle quantity: 5584) airport ground handling equipment. The intend of this study was to enable accurate estimations based on all possible decisions and help DMs satisfy company purchasing requirements. DMs often have difficultly choosing the most suitable supplier when various alternatives are available.

To ensure that our model had real-word utility, a decision expert team was structured; it comprised of two vice presidents with responsibility for AGHS company and four mechanical supply and repairs managers employed by TIAS. Ultimately, a foundation for such decisions was provided for applying the aforementioned steps, ensuring optimal decision-based outcomes [36]. 
Develop AGHS equipment selection criteria

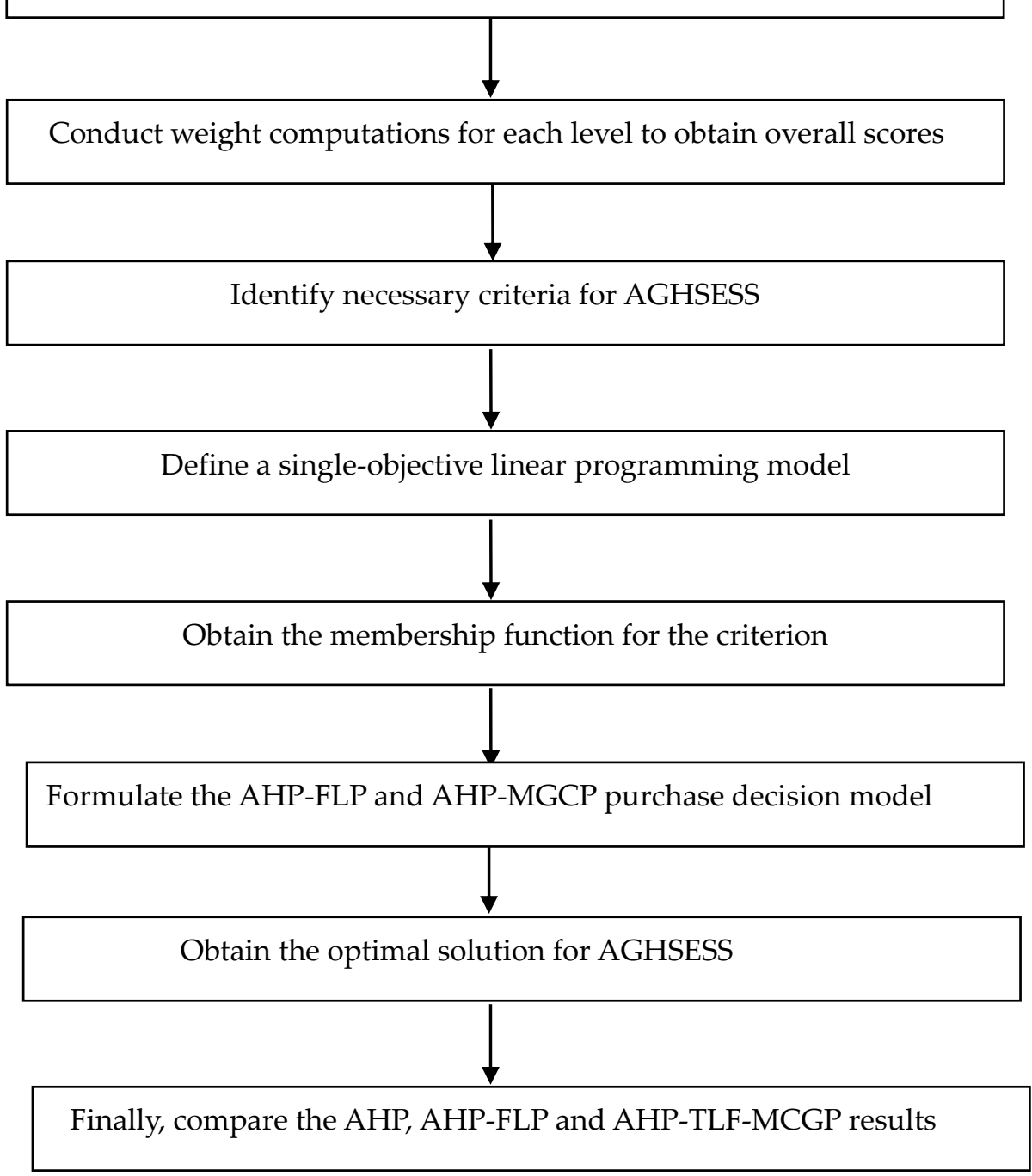

Figure 2. Steps of the proposed method.

\subsection{Identification of Necessary Decision Criteria for Equipment Selection}

The main decision criteria should relate to the choice of AGHS equipment suppliers, which are ultimately decided by expert team. The experience and qualification of the expert team were harnessed to decide on the vital criteria for AGHSESS. Details of the equipment supplier decision criteria are provided in Table 1 [14].

According to the aforementioned criteria, the AGHS equipment suppliers that were below enlargement or in procedure were examined, and a decision-making team chose six major supplier criteria that matched the company's needs. The six criteria are outlined as follows: Quality management (SC1), good production capacity and maintenance (SC2), product warranty (SC3), technical transfer provision (SC4), good cooperative relationship and reputation (SC5), and reasonable prices for parts (SC6). These criteria were used in our assessment and a decision hierarchy was subsequently constructed. The decision hierarchy based on the chosen AGHS equipment suppliers and their criteria is presented in Figure 3. 


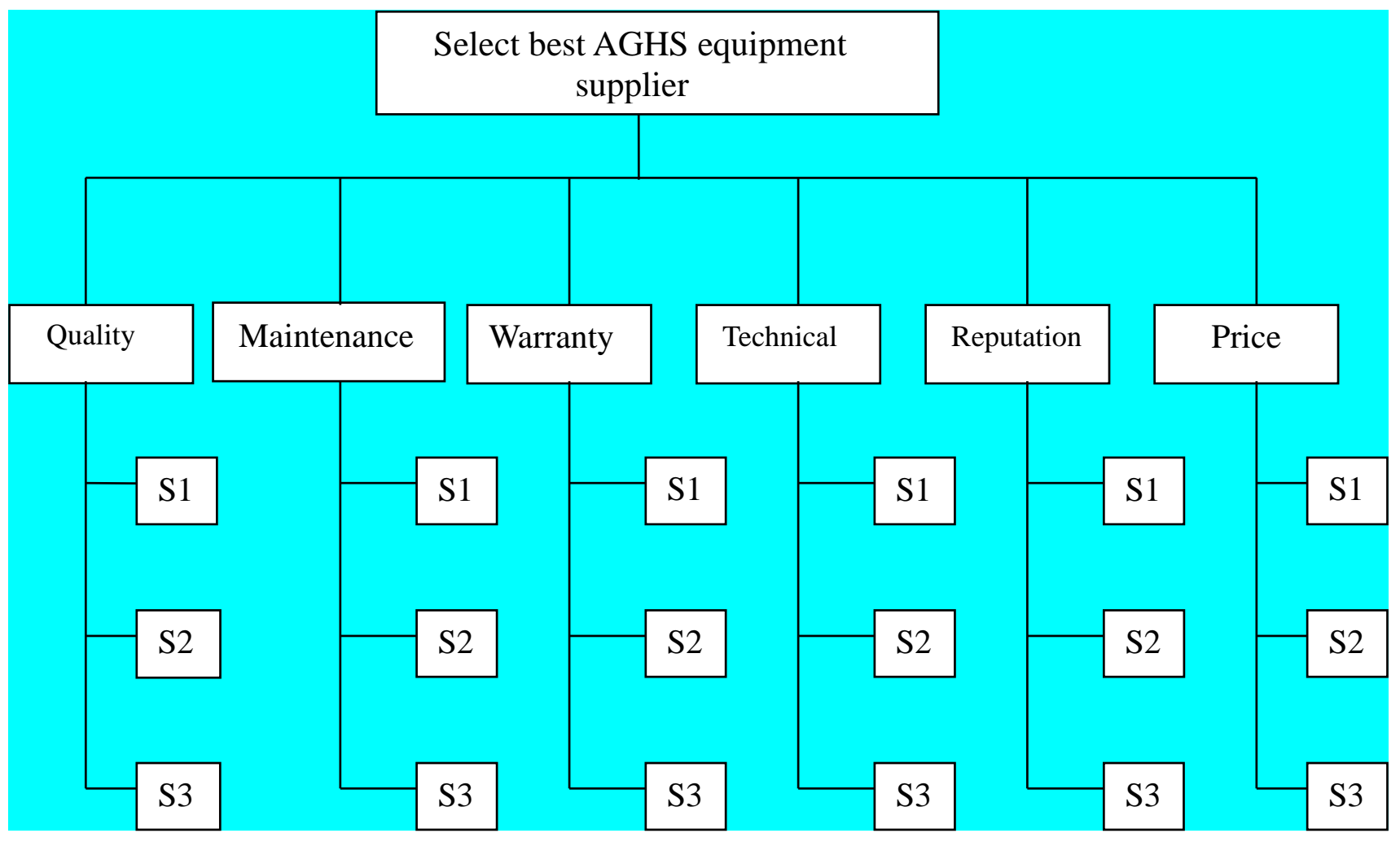

Figure 3. Decision hierarchy.

\subsection{Calculation of Criteria Weights}

Decision hierarchy criteria weights for use to calculate were computed using the AHP. Accordingly, the expert team developed a pairwise comparison matrix using the scale provided in Table 2. The geometric indices related to assessments were determined to establish a pair-wise comparison template, and broad agreement was reached on its content (Table 3). The results of the calculations based in Tables 4 and 5 [24].

Through the AHP, SC1 (quality management), SC4 (product warranty), and SC6 (providing technical transfer) were determined as the three vital criteria in the equipment DM process. A pairwise comparison template of the reliability coefficient of the existed revealed designate $0.084<0.1$. Therefore, the weights were determined to be reliable, and they were used in the following decision-making procedures [24].

\subsubsection{Constructing a Linear Programming Model for Real-World Application}

The supplier DM process was founded on the assessments of our decision expert team. This result was that all suppliers could be analyzed by referring to the six aforementioned criteria and pairwise comparison could be made based on the key criteria. Tables 5-7 presents the evaluation criteria for each equipment provider, which was derived with reference to the key supplier decision criteria.

Details of the linear programming model used for AGHSESS are presented in [5]. A linear membership function is used for fuzzifying (i.e., to render unclear or vague) the purpose utilities with the resource constraints indicated in the aforementioned selection problem. The dataset used to set standards for the lower $\left(z_{k}^{\min }\right)$ and upper $\left(z_{k}^{\max }\right)$ bounds of purpose utilities is presented in Table 8.

\subsubsection{Fuzzy Multi-Objective Decision Model}

The relationship between the six criteria and related weights are presented herein to maximize the presentation of the providers associated with all key AGHS decision factors. Accordingly, we can derive quality criteria to determine the utility of $Z_{1}$. 
The utility of $z_{1}$ (quality), which is shown in Figure 4, can be calculated according through Equation (8):

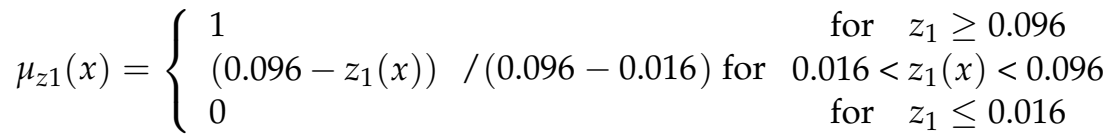

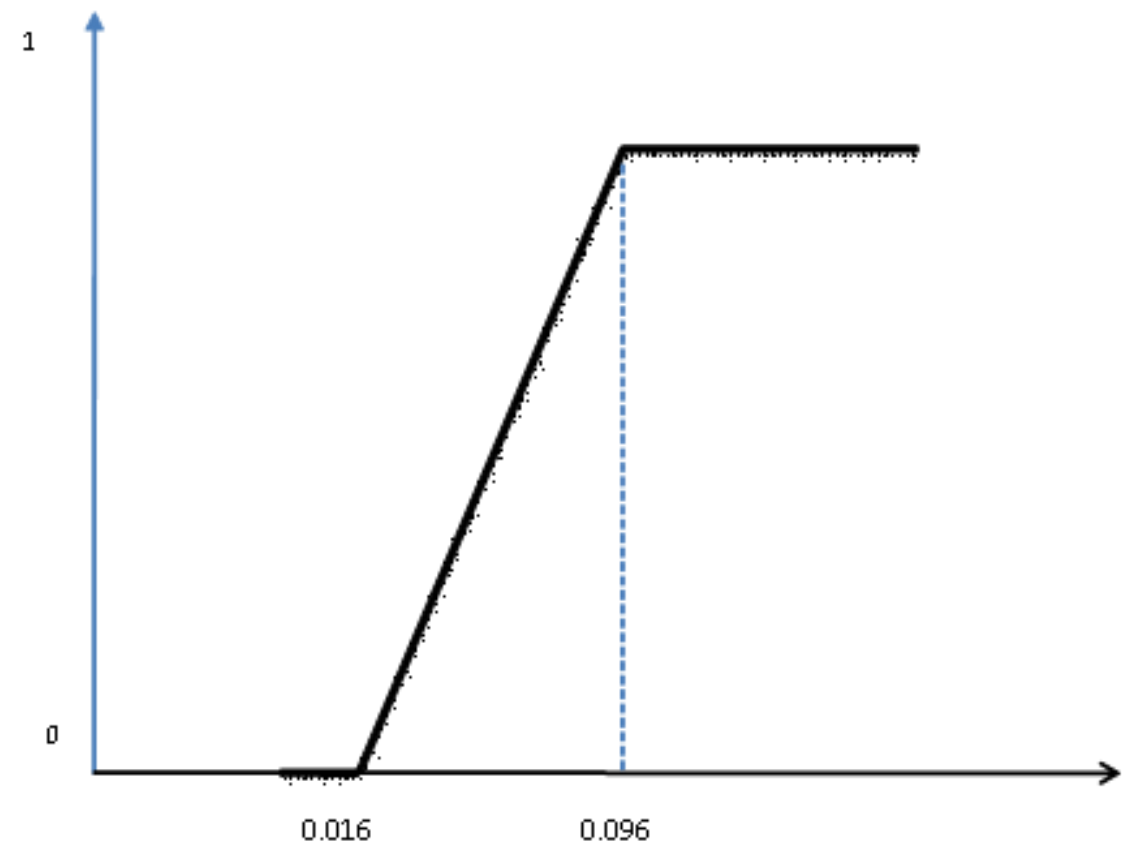

Figure 4. Membership function of quality.

On the basis of this condition, the following fuzzy linear model can be derived:

Obtain a vector $X$, where $X=\left[x_{1}, x_{2}, x_{3}\right]$ toward assure:

$$
\begin{aligned}
& \max \widetilde{z}_{1}=0.096 x_{1}+0.039 x_{2}+0.016 x_{3} \sim z_{1}^{0} \\
& \max \widetilde{z}_{2}=0.005 x_{1}+0.014 x_{2}+0.043 x_{3} \sim z_{2}^{0} \\
& \max \widetilde{z}_{3}=0.005 x_{1}+0.021 x_{2}+0.053 x_{3} \sim z_{3}^{0} \\
& \max \widetilde{z}_{4}=0.014 x_{1}+0.156 x_{2}+0.071 x_{3} \sim z_{4}^{0} \\
& \max \widetilde{z}_{5}=0.004 x_{1}+0.024 x_{2}+0.011 x_{3} \sim z_{5}^{0} \\
& \max \widetilde{z}_{6}=0.271 x_{1}+0.111 x_{2}+0.045 x_{3} \sim z_{6}^{0}
\end{aligned}
$$

subject to:

$$
\begin{aligned}
& x_{1}+x_{2}+x_{3}=1 \\
& x_{i} \geq 0, i=1,2,3 .
\end{aligned}
$$

\subsubsection{Formulation of the AHP-FLP Purchase Decision Model}

In this case, the weights $\left(w_{k}\right)$ related to the $k$ th objective are obtained pair-wise comparison of the key decision criteria determined using AHP are presented in Table 7, such as "line middling". Tables 5-7 are an indication that the total weights are equivalent to 1 (details of the approach are provided in [14]).

After the formulation of the AHP-FLP decision model and resolution of Equations (6)-(13), the single-objective model, which relates to the aforementioned fuzzy linear purchasing decision model, can be described as follows:

$$
\operatorname{Max} 0.151 \lambda_{1}+0.062 \lambda_{2}+0.079 \lambda_{3}+0.241 \lambda_{4}+0.039 \lambda_{5}+0.428 \lambda_{6}
$$


subject to:

$$
\begin{aligned}
& \lambda_{1} \leq \frac{0.096-(0.096 \times 1+0.039 \times 2+0.016 \times 3)}{0.096-0.016} \\
& \lambda_{2} \leq \frac{0.043-(0.005 \times 1+0.014 \times 2+0.043 \times 3)}{0.043-0.005} \\
& \lambda_{3} \leq \frac{0.053-(0.005 \times 1+0.021 \times 2+0.053 \times 3)}{0.053-0.005} \\
& \lambda_{4} \leq \frac{0.1564-(0.014 \times 1+0.156 \times 2+0.071 \times 3)}{0.156-0.014} \\
& \lambda_{5} \leq \frac{0.024-(0.004 \times 1+0.024 \times 2+0.011 \times 3)}{0.024-0.004} \\
& \lambda_{6} \leq \frac{0.271-(0.271 \times 1+0.111 \times 2+0.045 \times 3)}{0.271-0.045} \\
& \lambda_{i} \geq 0, \lambda_{i} \leq 1, i=1,2,3,4,5,6
\end{aligned}
$$

\subsubsection{Solving the AHP-FLP Purchase Decision Problem}

After the Lingo [39] was used to resolve this AGHS equipment provider problem, the best result was obtained as follows:

$x_{1}=0, x_{2}=0, x_{3}=1$, indicating that equipment provider A3 was the optimal choice according to the DMs preferences.

Objective $\left(Z_{k}\right)$ and membership $\left(\mu_{z k}(x)\right.$ or $\left.\lambda_{k}\right)$ functions for quality assessment can be expressed as follows:

$$
\begin{gathered}
z_{1}=0.016, z_{2}=0.043, z_{3}=0.053, z_{4}=0.071, z_{5}=0,011, z_{6}=0.045 \\
\mu_{z 1}(x)=\lambda_{1}=0, \mu_{z 2}(x)=\lambda_{2}=1, \mu_{z 3}(x)=\lambda_{3}=1, \mu_{z 4}(x)=\lambda_{4}=0.401, \\
\mu_{z 5}(x)=\lambda_{5}=0.350, \mu_{z 6}(x)=\lambda_{6}=0 .
\end{gathered}
$$

The quality assessments showed that the values for $Z_{3}$, (product warranty), $Z_{4}$, (technical transfer), and $Z_{6}$, (reasonable prices for parts) were higher than those for $Z_{1}$, (quality management), $Z_{2}$, (production capacity and maintenance), and $Z_{5}$, (good cooperative relationship and reputation). The success of the model depends on the DM's preferences and the related decision criteria Equipment supplier A3 was the optimal choice in this context.

\subsubsection{Comparison of AHP-TLF-FLP and AHP-TLF-MCGP Model Results}

For the sake of reducing the AHP and AHP-FLP model approaches' drawbacks and reaching precise results, in this solution, corresponding to DM's preferences ( $w 1=0.8$, $\mathrm{w} 2=0.2$ ), Table 12 presents AHP-TLF-MCGP model solution programming to solve AGHSESS problem.

After, Lingo was used to resolve the aforementioned AGHSESS decision problem, and the optimal resolution derived from the AHP-TLF-MCGP model is outlined as follows: $x_{1}=0, x_{2}=0, x_{3}=1, y_{1}=0.016, y_{2}=0, y_{3}=0.005, y_{4}=0.014, y_{5}=0.004, y_{6}=0.045$, $y_{7}=0.215$. The finding that supplier A3 was the most appropriate one in the AHP-TLFMCGP approach confirmed the views of the AGHSESS team.

The AHP, TLF, FLP, and MCGP approaches outperformed the AHP approach in solving the AGHSESS problem when supplier selection criteria were imposed. When AHP model was used without constraints, Supplier A1 was identified as the optimal one. This contradicts the AHP-FLP and AHP-TLF-MCGP models results in that Supplier A3 was determined to be the best option. In AGHSESS problems, the AHP-TLF-MCGP model can effectively handle vague and imprecise input data and criteria with varying relative weights. The AHP-TLF-MCGP model was implemented by integrating the AHP and TLF methods with MCGP to solve AGHSESS problems. This decision model can assist the DMs determine the suitable stock to order from each AGHS supplier provider, and it permits purchasing managers to easily select the optimal supplier in terms of criteria such as quality management, production capacity, product maintenance, product warranty, technical transfer provision, good cooperative relationship, and reputation, and reasonable prices for parts. With a few modifications, the model can also be in the habit of overcome other DM problems, such as those encountered by an overseas AGHS provider or others aviation industry firms. 


\section{Conclusions and Implications}

\subsection{Conclusions}

The results obtained from the AHP and AHP-FLP decision model are compared in Table 13. The total scores for all providers are provided in this table; such scores were obtained using the aforementioned purchase decision model. As indicated, when the AHP model was used, equipment supplier A1 was recognized as the best choice when no constraints were imposed. When the AHP-FLP model was used and constraints were imposed, equipment supplier A3 was determined to be the best choice. This finding confirmed the postulations of the supplier selection team, giving credence to the argument that the AHP-FLP model would outperform the AHP model in this context.

Table 13. Comparison of the AHP, AHP-fuzzy linear programming (FLP), and AHP-TLF-MCGP model purchase decision model results.

\begin{tabular}{lccc}
\hline & AHP & AHP-FLP & AHP-TLF-MCGP \\
\hline AGHS equipment supplier A1 & $0.385^{*}$ & 0.000 & 0.000 \\
AGHS equipment supplier A2 & 0.370 & 0.000 & 0.000 \\
AGHS equipment supplier A3 & 0.097 & 1.000 & 1.000 \\
\hline Note: $0.385^{*}=0.574 \times 0.151+0.077 \times 0.062+0.064 \times 0.079+0.057 \times 0.241+0.096 \times 0.039+0.633 \times 0.428$.
\end{tabular}

AGHSESS is a pertinent concern and affects AGHS providers in terms of staff members' daily duties and work safety. In our study, we compared AHP and AHP-FLP decision models to evaluate the selection of AGHS equipment suppliers. We used triangular fuzzy numbers to conduct linguistic assessments in order to assess the individual decisions of experts; subsequently, we derived the AHP-FLP and AHP-TLF-MCGP decision models for making group assessments. To provide a real-world example, we conduct a case study on an AGHS supplier in Taiwan. The AHP-FLP and AHP-TLF-MCGP decision model outperformed the AHP technique in terms of AGHSESS under conditions of limited selection criteria. Of the six AGHS equipment suppliers for the AGHS company considered in our case study, supplier A1 was determined to be the optimal supplier when the AHP model was used without constraints imposed. After the AHP-FLP and AHP-TLF-MCGP model was used, supplier A3 was determined to be the most suitable choice. In this case study, this model could deal with inaccurately entered information and criteria with varying relative weights. The results through the AHP-FLP and AHP-TLF-MCGP model corresponded to the real-world AGHSESS decisions of purchasing managers.

\subsection{Management Implications}

In this study, AHP and AHP-FLP models were compared in terms of how they helped personal deal with supplier selection problems. The integrated model can enable the aviation industry purchasing managers to observe all their options clearly under considerations of quality management, production capacity, product maintenance, product warranty, technical transfer provision, good cooperative relationship and reputation, and reasonable prices for parts. Two advantages are gained from using the AHP-TLF-MCGP model to solve AGHSESS problems: First, it permits DMs to set multiple desire levels related to supplier provider criteria, and second, it facilitates problem solving. Furthermore, the AHPTLF-MCGP model is possibly beneficial on behalf of solving different MCDM problems, for instance those involving vague data.

\subsection{Limitations}

We combined the TLF and MCGP models that were integrated with the AHP model to capture the AGHSESS problem of fuzziness in human judgment and account for resource constraints. To reduce the AHP and AHP-FLP model approaches' disadvantages and reach precise outcomes, we compared them with the AHP-TLF-MCGP decision model to verify the AGHSESS problem. Formerly, if DMs use a new AHP technique and a 
combination of other goal programming methodologies, there can be a dissimilar result in hesitant situations.

\subsection{Future Research Directions}

Individual constraints in this model are a concern when the multiattribute weighting method is used [40]. The weights chosen to be used in the AHP technique may be regarded as biased. The data envelopment analysis (DEA) technique partly entails an optimization process conducted using linear programming; therefore, it can be used to determined weights. Several authors such as Pitchipoo, $[37,41]$ have indicated that weights may be determined using DEA. These weights can be derived independently and thus involve less bias compared with those derive through other techniques. Accordingly, future research can be conducted on the use of this technique for deriving weights in our proposed model.

Author Contributions: Conceptualization, Y.-J.T.; formal analysis, C.-S.T. and Y.-J.T.; writing; planning all works in the study and supervision, H.-S.L.- original draft. All authors have read and agreed to the published version of the manuscript.

Funding: This research received no external funding.

Institutional Review Board Statement: Not applicable.

Informed Consent Statement: Not applicable.

Data Availability Statement: Not applicable.

Conflicts of Interest: The authors declare no conflict of interest.

\section{References}

1. Shen, C.W.; Peng, Y.T.; Tu, C.S. Multi-criteria decision-making techniques for solving the airport ground handling service equipment vendor selection problem. Sustainability 2019, 11, 3466. [CrossRef]

2. Inan, T. Performance measurement system (PSM) and balanced scorecard (BSC) strategies used in the process related with ramp handling services of ground handling management. J. Aviat. 2018, 2, 1-9.

3. Fuhr, J.; Beckers, T. Vertical governance between airlines and airport: A transaction cost analysis. Rev. Netw. Econ. 2006, 5, 386-412. [CrossRef]

4. Schmidberger, S.; Bals, L.; Hartmann, E.; Jahns, C. Ground handling services at European hub airports: Development of a performance measurement system for benchmarking. Int. J. Prod. Econ. 2009, 117, 104-116. [CrossRef]

5. Sevkli, M.; Koh, S.C.L.; Zaim, S.; Demirbag, M.; Tatoglu, E. Hybrid analytical hierarchy process model for supplier selection. Ind. Manag. Data Syst. 2008, 108, 122-142. [CrossRef]

6. Dulmin, R.; Mininno, V. Supplier selection using a multi-criteria decision aid method. J. Purch. Suppl. Manag. 2003, 9, 177-187. [CrossRef]

7. Amid, A.; Ghodsypour, S.H.; O’Brien, C. Fuzzy multiobjective linear model for the supplier selection in a supply chain. Int. J. Prod. Econ. 2006, 104, 394-407. [CrossRef]

8. Wang, T.C.; Chang, T.H. Application of TOPSIS in evaluating initial training aircraft under a fuzzy environment. Expert Syst. Appl. 2007, 33, 870-880. [CrossRef]

9. Ayag, Z. An analytic-hierarchy-process based simulation model for implementation and analysis of computer-aided systems. Int. J. Prod. Res. 2002, 40, 3053-3073. [CrossRef]

10. Ayă̆, Z.; Özdemir, R.G. A fuzzy AHP approach to evaluating machine tool alternatives. J. Intell. Manuf. 2006, 17, 179-190. [CrossRef]

11. Monczka, R.M.; Nichols, E.L., Jr.; Callahan, T.J. Value of supplier information in the decision process. Int. J. Purch. Mater. Manag. 1992, 28, 20-30.

12. Vonderembse, M.A.; Tracey, M. The impact of supplier selection criteria and supplier involvement on manufacturing performance. J. Supply Chain Manag. 1999, 35, 33-39. [CrossRef]

13. Bhutta, K.S.; Huq, F. Supplier selection problem: A comparison of the total cost of ownership and analytic hierarchy process approaches. Supply Chain Manag. Int. J. 2002, 7, 126-135. [CrossRef]

14. Sarkis, J.; Talluri, S. A model for strategic supplier selection. J. Supply Chain Manag. 2002, 38, 18-28. [CrossRef]

15. Goztepe, K.; Kahraman, C. A new approach to military decision making process: Suggestions from MCDM point of view. In Proceedings of the International Conference on Military and Security Studies, İstanbul, Turkey, 10-11 March 2015 ; pp. 118-122.

16. Ordoobadi, S.M. Application of AHP and Taguchi loss functions in supply chain. Ind. Manag. Data Syst. 2010, 110, 1251-1269. [CrossRef] 
17. Liao, C.N.; Kao, H.P. Supplier selection model using Taguchi loss function, analytical hierarchy process and multi-choice goal programming. Comput. Ind. Eng. 2010, 58, 571-577. [CrossRef]

18. Magdalena, R. Supplier selection for food industry: A combination of taguchi loss function and fuzzy analytical hierarchy process. Asian J. Technol. Manag. 2012, 5, 13-22.

19. Ordoobadi, S.M. Application of AHP and Taguchi loss functions in evaluation of advanced manufacturing technologies. Int. J. Adv. Manuf. Tech. 2013, 67, 2593-2605. [CrossRef]

20. Saaty, T.L. The Analytic Hierarchy Process: Planning, Priority Setting, Resource Allocation; RWS Publications: Pittsburgh, PA, USA, 1988.

21. Chan, F.T.S.; Kumar, N.; Tiwari, M.K.; Lau, H.C.W.; Choy, K.L. Global supplier selection: A fuzzy-AHP approach. Int. J. Prod. Res. 2008, 46, 3825-3857. [CrossRef]

22. Dağdeviren, M.; Yüksel, I. Developing a fuzzy analytic hierarchy process (AHP) model for behavior-based safety management. Inform. Sci. 2008, 178, 1717-1733. [CrossRef]

23. Kulak, O.; Durmusoglu, B.; Kahraman, C. Fuzzy multi-attribute equipment selection based on information axiom. J. Mater. Proces. Technol. 2005, 169, 337-345. [CrossRef]

24. Dağdeviren, M.; Yavuz, S.; Kılınç, N. Weapon selection using the AHP and TOPSIS methods under fuzzy environment. Expert Syst. Appl. 2008, 36, 8143-8151. [CrossRef]

25. Saaty, T.L. Decision making with the analytic hierarchy process. Int. J. Serv. Sci. 2008, 1, 83-98. [CrossRef]

26. Taguchi, G.; Phadke, M.S. Quality Engineering through Design Optimization. In Quality Control, Robust Design, and the Taguchi Method; Dehnad, K., Ed.; Springer: Boston, MA, USA, 1989.

27. Taguchi, G.; Elsayed, E.; Hsiang, T. Quality Engineering in Production System; McGraw-Hill: New York, NY, USA, 1989.

28. Ealey, L.A. Quality by Design: Taguchi Methods and US Industry; ASI Press: Bloomington, IN, USA, 1988.

29. Besterfield, D.H.; Besterfield-Michna, C.; Besterfield, G.H.; Besterfield-Sacre, M. Total Quality Management, 3rd ed.; Prentice-Hall Inc.: Upper Saddle River, NJ, USA, 2003.

30. Bellman, R.G.; Zadeh, L. A Decision making in a fuzzy environment. Manag. Sci. 1970, 30, 141-164. [CrossRef]

31. Zimmermann, H.J. Fuzzy programming and linear programming with several objective functions. Fuzzy Sets Syst. 1978, 1, 45-55. [CrossRef]

32. Chang, C.T. Revised multi-choice goal programming. Appl. Math. Model. 2008, 32, 2587-2595. [CrossRef]

33. Tiwari, R.N.; Dharmahr, S.; Rao, J.R. Fuzzy goal programming an additive model. Fuzzy Sets Syst. 1987, 24, 27-34. [CrossRef]

34. Haleh, H.; Hamidi, A. A fuzzy MCDM model for allocating orders to suppliers in a supply chain under uncertainty over a multi-period time horizon. Exp. Syst. Appl. 2011, 38, 9076-9083. [CrossRef]

35. Lai, Y.J.; Hawang, C.L. Fuzzy Multiple Objective Decision Making, Methods and Applications; Springer: Berlin/Heidelberg, Germany, 1994.

36. Mortezaa, Z.; Rezab, F.M.; Seddiqc, M.M.; Shararehd, P.; Jamale, G. Selection of the optimal tourism site using the ANP and fuzzy TOPSIS in the framework of Integrated Coastal Zone Management: A case of Qeshm Island. Ocean Coast. Manag. 2016, 130, 179-187. [CrossRef]

37. Pitchipoo, P.; Venkumar, S.; Rajakarunakaran, K.M. Modelling and development of decision model for supplier selection in process industry. Int. J. Comput. Aided Eng. Tech. 2011, 3, 504-516. [CrossRef]

38. Fashoto, S.G.; Akinnuwesi, B.; Owolabi, O.; Adelekan, D. Decision support model for supplier selection in healthcare service delivery using analytical hierarchy process and artificial neural network. Afr. J. Bus. Manag. 2016, 10, $209-232$.

39. Schrage, L. LINGO Release 8.0; LINGO System Inc.: Chicago, IL, USA, 2002.

40. Wang, J.J.; Yang, D.L. Using a hybrid multi-criteria decision aid method for information systems outsourcing. Comput. Oper. Res. 2007, 34, 3691-3700. [CrossRef]

41. Lee, Z.-Y.; Chu, M.T.; Wang, Y.T.; Chen, K.J. Industry performance appraisal using improved MCDM for next generation of Taiwan. Sustainability 2020, 12, 5290. [CrossRef] 